\author{
A. Otsuka - K. Azuma $\cdot$ T. Iesaki - F. Sato $\cdot$ T. Hirose $\cdot$ \\ T. Shimizu $\cdot$ Y. Tanaka $\cdot$ H. Daida $\cdot$ \\ R. Kawamori $\cdot$ H. Watada
}

\title{
Temporary hyperglycaemia provokes monocyte adhesion to endothelial cells in rat thoracic aorta
}

Received: 19 May 2005 / Accepted: 11 July 2005 / Published online: 8 November 2005

C) Springer-Verlag 2005

\begin{abstract}
Aims/hypothesis: Several epidemiological data suggest that patients with postprandial hyperglycaemia are at high risk of cardiovascular disease. The aim of this study was to elucidate the effect of a glucose 'spike' on monocyte adhesion to rat aortic endothelial cells. Materials and methods: Monocyte adhesion to endothelial cells in vivo was quantitated using an en face method for observation of endothelial surface after immunohistochemical staining for CD68 in the thoracic aortas of Sprague-Dawley rats after several kinds of blood glucose rises. Results: The number of monocytes adhering to endothelial cells increased at $30 \mathrm{~min}$ after injection of glucose in 8-week-old Sprague-Dawley rats. The increased adhesion returned to the basal level at $120 \mathrm{~min}$ after glucose injection, concomitantly with the return of blood glucose levels to normal. The infusion of octreotide to inhibit endogenous insulin secretion did not prevent the glucose-induced increase in monocyte adhesion to endothelial cells. On the other hand, the number of monocytes adhering to endothelial cells did not increase in rats with streptozotocin-induced diabetes and sustained hyperglycaemia. Conclusions/interpretation: Our data demonstrate that a temporary rise in blood glucose levels can in itself promote a reversible increase in monocyte adhesion to arterial endothelial cells.
\end{abstract}

\footnotetext{
A. Otsuka - K. Azuma - F. Sato · T. Hirose - T. Shimizu ·

Y. Tanaka $\cdot$ R. Kawamori $\cdot$ H. Watada $(\bowtie)$

Department of Medicine, Metabolism and Endocrinology,

Juntendo University School of Medicine,

2-1-1 Hongo, Bunkyo-ku,

113-8421, Tokyo, Japan

e-mail: hwatada@med.juntendo.ac.jp

Tel.: +81-3-58021579

Fax: $+81-3-38135996$
}

T. Iesaki $\cdot$ H. Daida

Department of Cardiology,

Juntendo University School of Medicine,

Tokyo, Japan
Keywords Cardiovascular disease - Glucose spike · Monocyte-endothelial interaction · NEMOes ·

Postprandial hyperglycaemia

Abbreviations NEMOes: New en face method for optimal observation of endothelial surface $\cdot$ SD: SpragueDawley - UKPDS: UK Prospective Diabetes Study

\section{Introduction}

Patients with diabetes are at high risk of cardiovascular disease $[1,2]$ and hyperglycaemia is thought to exert a harmful effect on the arterial wall. For example, the UK Prospective Diabetes Study (UKPDS) 35 identified a positive association between mean $\mathrm{HbA}_{1} \mathrm{c}$ value and ischaemic heart disease. However, the relation between macroangiopathy and $\mathrm{HbA}_{1} \mathrm{c}$ value was weaker than that observed for microangiopathy [3]. In addition, according to UKPDS 33, intensive treatment leading to a $\sim 1 \%$ reduction in $\mathrm{HbA}_{1} \mathrm{c}$ value can significantly reduce the risk of microangiopathy, but cannot significantly reduce the risk of macroangiopathy [4]. In contrast, recent epidemiological data suggest that postprandial hyperglycaemia might be a discrete risk factor for cardiovascular disease that is independent of and more powerful than the risk associated with fasting hyperglycaemia or $\mathrm{HbA}_{1} \mathrm{c}$ values [5-9]. These findings suggest that a glucose 'spike' might be associated with the onset of cardiovascular disease. However, subjects with postprandial hyperglycaemia often have other risk factors connected with insulin resistance states. Thus, the contribution of a glucose 'spike' in itself to the progression of atherosclerosis has not been fully elucidated.

Atherosclerosis is a complex disease process promoted by various factors. A growing body of evidence invokes a role for monocyte-endothelial interactions in the disease's pathophysiology. Indeed, the adherence of circulating monocytes to the endothelial lining of large arteries is one of the earliest detectable events in human and experimental atherosclerosis. It has been proposed that the subsequent transendothelial migration of these adherent 
monocytes, their accumulation in the intima and transformation into lipid-engorged foam cells result in the formation of atherosclerotic plaques $[10,11]$.

Several experimental methods have been employed to observe monocyte adhesion to endothelial cells, among them a new en face method for optimal observation of endothelial surface (NEMOes) that was recently established by us. This method [12] facilitates observation of the entire endothelial surface with a clear focused image, thus enabling quantitation of the precise number of monocytes adhering to a specific region of the rat thoracic aorta after immunostaining for the monocyte/macrophage-specific protein, CD68.

In the present study, as a first step towards elucidating the effect of a glucose 'spike' on monocyte adhesion to endothelial cells in vivo, we injected glucose intravenously into Sprague-Dawley (SD) rats. The NEMOes procedure was then applied to quantitate monocyte adhesion to endothelial cells in the thoracic aorta. The results demonstrated that an acute rise in blood glucose promoted monocyte adhesion to endothelial cells independently of insulin level. On the other hand, sustained hyperglycaemia did not increase the number of monocytes adhering to endothelial cells. Our results suggest that the glucose 'spike' has a distinct role in the initial phase of atherosclerosis.

\section{Materials and methods}

Animals This study was approved by the Animal Care and Use Committee of Juntendo University, Tokyo. Specificpathogen-free male SD rats were purchased from Charles River Japan (Kanagawa, Japan). All rats were housed in stainless steel wire cages (two to three animals per cage) in a temperature-controlled clean room with a 12-hour lightdark cycle. The animals had free access to rat chow (Oriental Yeast, Tokyo, Japan) and autoclaved tap water. Some rats were injected intravenously with streptozotocin (30 mg/kg) (Sigma-Aldrich, St. Louis, MO, USA) dissolved in citrate buffer ( $\mathrm{pH} 4.5)$.

Intravenous glucose load To evaluate the influence of a rapid rise in blood glucose on endothelial damage, we injected glucose $(5.5 \mathrm{mmol} / \mathrm{kg})$ via the femoral vein into SD rats at the age of 8 weeks after overnight fasting. As controls, mannitol $(1 \mathrm{~g} / \mathrm{kg})$ or saline $(2.0 \mathrm{ml} / \mathrm{kg})$ were also administered intravenously to each of the SD rats. Under these conditions, we removed thoracic aortas before and at $30 \mathrm{~min}$ and $120 \mathrm{~min}$ after the load of each agent $(n=5$ at each time point for each group). In addition, blood samples were taken from the tail veins of another five rats and used to measure blood glucose and insulin levels at 0,30 , 60 and $120 \mathrm{~min}$ after the glucose injection. Some SD rats $(n=10)$ were injected continuously via the femoral vein with $0.1 \mu \mathrm{g} \mathrm{kg}^{-1} \mathrm{~min}^{-1}$ octreotide (Novartis Pharma, Tokyo, Japan) using an infusion pump (PHD 2000 infusion; Harvard Apparatus, Holliston, MA, USA). Thirty minutes after the beginning of the infusion, $4.4 \mathrm{mmol} / \mathrm{kg}$ of glucose was injected via the femoral vein in five SD rats. The remaining rats $(n=5)$ were used as controls. Blood samples were taken every $5 \mathrm{~min}$.

Hyperinsulinaemic-englycaemic clamps We performed the clamps on SD rats $(n=5)$ to maintain blood glucose concentrations $(\sim 4.4 \mathrm{mmol} / \mathrm{l})$ during human insulin infusion $\left(30 \mathrm{pmol} \mathrm{kg}^{-1} \mathrm{~min}^{-1}\right)$ by infusing glucose at variable rates. The rats had previously fasted overnight. Control rats $(n=4)$ were infused with $0.02 \mathrm{ml} \mathrm{kg}^{-1} \mathrm{~min}^{-1}$ saline. Blood samples were taken every $5 \mathrm{~min}$ to measure relevant parameters.

Laboratory data The plasma glucose concentration was measured by the glucose oxidase method using a glucose sensor (Glutest; Sanwa Kagaku, Nagoya, Japan). Plasma insulin was measured using an insulin ELISA kit (Morinaga, Takamatsu, Japan). $\mathrm{HbA}_{1} \mathrm{c}$, total cholesterol, NEFA, and triglycerides were measured by SRL (Tachikawa, Japan).

NEMOes Within 5 min of finishing various interventions, the rats were killed under anaesthesia induced by intraperitoneal injection of sodium pentobarbital $(50 \mathrm{mg} / \mathrm{kg}$; Abbott Laboratories, Abbott Park, IL, USA). Soon after, fixation and tissue preparation were performed by systemic perfusion at a pressure of $180 \mathrm{~mm} \mathrm{H}_{2} \mathrm{O}$ via the left ventricle, with $500 \mathrm{ml}$ of normal saline followed by $300 \mathrm{ml}$ of $10 \%$ buffered formalin as early as possible. After fixation, the aorta was dissected carefully from the aortic arch to the lower thoracic region and immersed overnight at $4{ }^{\circ} \mathrm{C}$ in $10 \%$ buffered formalin. Next, the thoracic aorta was divided into 8 - to $12-\mathrm{mm}$-long segments and the proximal end of each segment was marked. Then each segment was placed in $1 \%$ hydrogen peroxidase in methanol for $20 \mathrm{~min}$ at room temperature. After rinsing three times with PBS, the segments were placed into 1.5$\mathrm{ml}$ microcentrifuge tubes (Treff, Degersheim, Switzerland) for incubation with the mouse anti-rat CD68 antibody (1:100 dilution: Serotec, Raleigh, NC, USA) in PBS for $60 \mathrm{~min}$ at $37^{\circ} \mathrm{C}$. Next, the specimens were incubated with biotinylated anti-mouse IgG for $30 \mathrm{~min}$ at room temperature in a new tube, followed by reaction with horseradish peroxidase-conjugated streptavidin with the aid of an LSAB2 kit (Dako, Carpinteria, CA, USA). Staining was completed after incubation with a substrate-chromogen solution. The segments were then cut open with scissors, this being done longitudinally along the ventral side. Each specimen was placed on a slide glass with the intimal side facing up and covered with a coverslip by surface tension. Specimens were viewed under a microscope (E800; Nikon, Tokyo, Japan) connected to an XYZ controller and a digital camera (Media Cybernetics, Silver Spring, MD, USA). Images were captured at various focal lengths with an automatically regulated Z-stepper and the clearest images were selected automatically to produce a composite image of the whole thoracic aorta using Image-Pro 4.5J (Planetron, Tokyo, Japan) [12]. 
Fig. 1 Monocyte adhesion after intravenous glucose injection. Blood glucose (a) and insulin (b) concentrations were measured at the indicated time points following intravenous injection of glucose $(5.5 \mathrm{mmol} / \mathrm{kg})$ into 8 -week-old SD rats $(n=5)$. Density of monocyte adhesion in SD rats at a branching site (c) and non-branching area (d) before and 30 and $120 \mathrm{~min}$ after intravenous injection of $2 \mathrm{ml} / \mathrm{kg} \mathrm{sa}-$ line (open bars), $1 \mathrm{~g} / \mathrm{kg}$ mannitol (grey bars), or $1 \mathrm{~g} / \mathrm{kg}$ glucose (filled bars) $(n=5$ at each time point of each group). All data are expressed as means \pm SEM. ${ }^{*} p<0.05$ vs saline injection group; ${ }^{*} p<0.05$ vs mannitol injection group. $\mathbf{e}$ and $\mathbf{f}$ Typical en face views of staining with CD68 at 30 min after injection of saline (e) or glucose (f) at age 8 weeks a

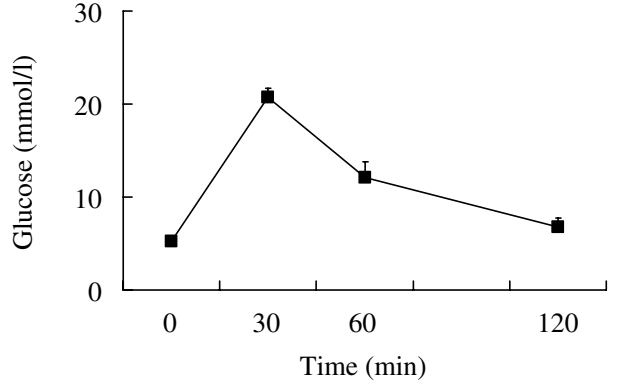

c

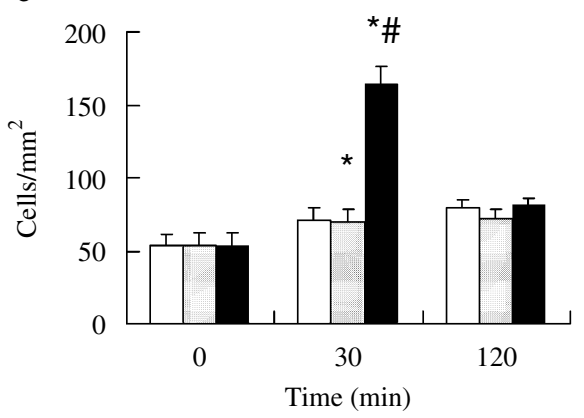

e

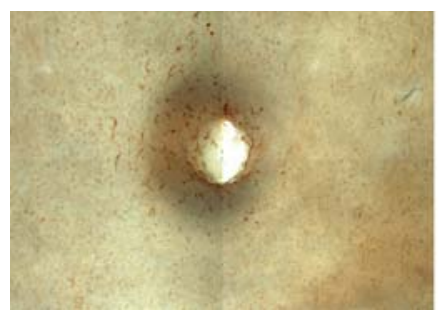

b

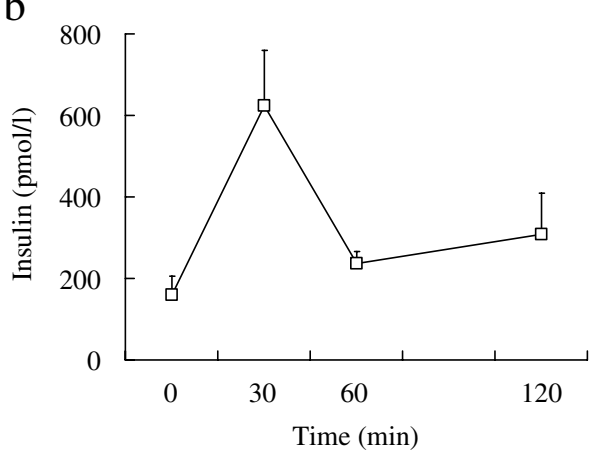

d

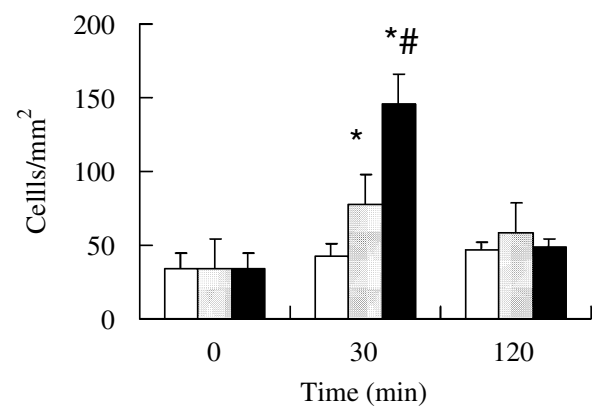

f

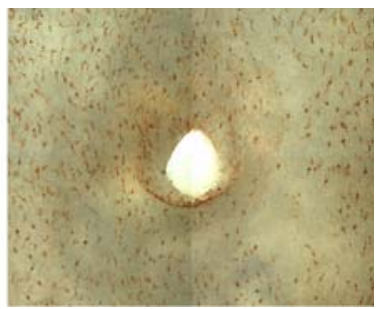

Cell counting To enumerate the monocytes adhering to the endothelium, we set the area as a rectangle with sides that were twice the length of the long and short diameters of the vessel opening, respectively, and with the rectangle

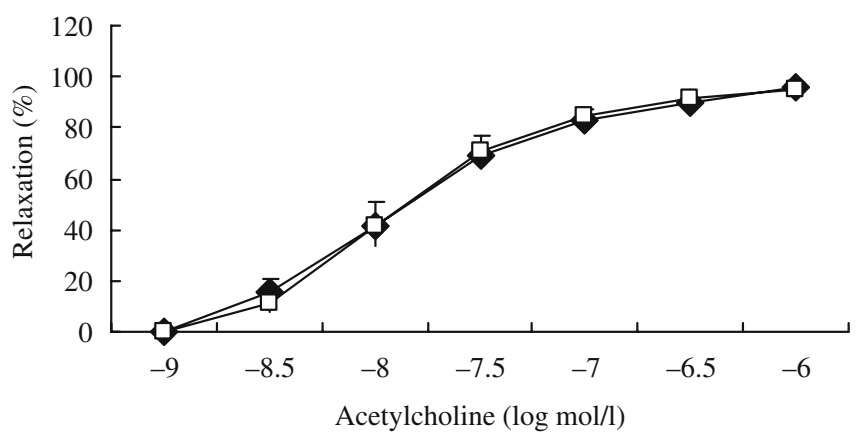

Fig. 2 Effect of intravenous injection of glucose on endotheliumdependent vasodilation. Glucose $(5.5 \mathrm{mmol} / \mathrm{kg}$ ) (filled symbol) or saline $(2 \mathrm{ml} / \mathrm{kg}$ ) (open symbol) were injected into 8-week-old SD rats. Thirty minutes after injection, five rats were killed and the thoracic aortas used for the vasodilation test. Data represent the dose-response curves for relaxation induced by acetylcholine. Percent relaxation was calculated as percentage of $0.1 \mu \mathrm{mol} / 1$ phenylephrine-induced contraction. All data are expressed as means \pm SEM centered on the opening. We defined the area bound by this rectangle as the area around the branching site and the area outside the rectangle was defined as the non-branching area [12]. The total numbers of CD68-immunopositive cells around the branching site and in the non-branching areas were counted separately in each aorta. The cell density in each area was then calculated as the cell count divided by the total area. Examiners were blinded to the treatment regimen.

Measurement of changes in force in rat thoracic aorta After rats were killed, descending thoracic aortas were isolated and cut into transverse rings ( $\sim 3 \mathrm{~mm}$ in width) and used to measure changes in force. Care was taken not to touch the endothelial surface to preserve the functional endothelium. The techniques used to measure changes in force in oxygenated Krebs bicarbonate buffer $\left(37^{\circ} \mathrm{C}\right)$ were adapted from previously described methods [13]. Optimal passive tension of $2 \mathrm{~g}$ was applied to vascular rings throughout the experiment. The vessels were initially exposed to high- $\mathrm{K}^{+}$Krebs bicarbonate buffer containing $\mathrm{KCl}$ instead of $\mathrm{NaCl}$, a treatment that produces maximal force generation and enhances the reproducibility of subsequent contractions. After washing, the vessels were submaxi- 
mally contracted with $0.1 \mu \mathrm{mol} / 1$ phenylephrine and, once a steady-state level of contraction was observed, endothelium-dependent relaxation elicited by an increasing cumulative concentration of acetylcholine was examined. Relaxation was expressed as percent change of the steadystate level of contraction.

Statistical analysis All data are expressed as the mean \pm SEM. Differences between groups were examined for statistical significance using the Student's unpaired $t$-test. A $p$ value of less than 0.05 denoted the presence of a statistically significant difference.

\section{Results}

A temporary rise in blood glucose provokes monocyte adhesion to endothelial cells in vivo To assess the effect of a temporary rise in blood glucose levels on monocyte adhesion to endothelial cells without the existence of an insulin-resistant state, we intravenously injected glucose $(5.5 \mathrm{mmol} / \mathrm{kg})$ into SD rats at the age of 8 weeks. As shown in Fig. 1, the blood glucose level at 30 min after glucose injection was $20.7 \pm 0.9 \mathrm{mmol} / \mathrm{l}$ and returned to the basal level at $120 \mathrm{~min}$ after injection. Similarly, the serum

a

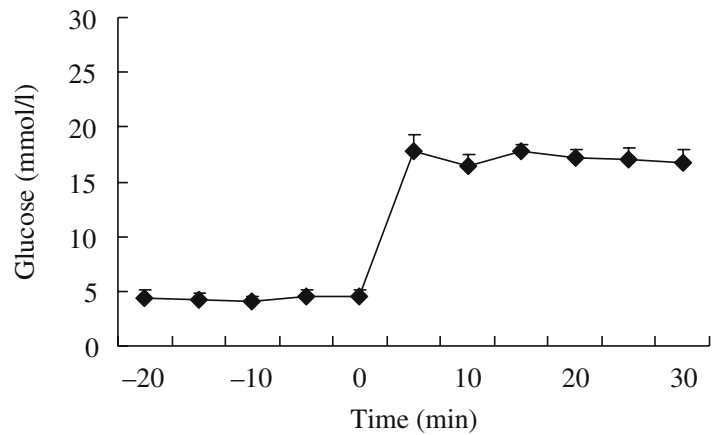

c

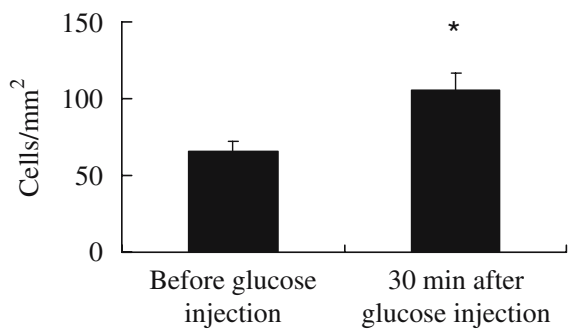

Fig. 3 Effect of suppression of insulin secretion during glucose load on monocyte adhesion to the endothelium. Octreotide $\left(0.1 \mu \mathrm{g} \mathrm{kg}^{-1} \mathrm{~min}^{-1}\right)$ was continuously infused (a and $\mathbf{b})$ into 8 -week-old SD rats from $30 \mathrm{~min}$ before the $4.4 \mathrm{mmol} / \mathrm{kg}$ glucose injection at $0 \mathrm{~min}$. The blood glucose (a) and insulin (b) concentrations were measured at the indicated time points. All data are expressed as means \pm SEM. The insulin level increased to $620.6 \pm 137.9 \mathrm{pmol} / 1$ at $30 \mathrm{~min}$ after the injection, returning to the basal level at $120 \mathrm{~min}$ after injection. Under these conditions, we removed thoracic aortas, before and at 30 and $120 \mathrm{~min}$ after glucose injections, and then investigated monocyte adhesion to endothelial cells. SD rats injected with the same volume of saline or mannitol served as controls. At 30 min after the glucose load, a significant increase in monocyte adhesion was observed (Fig. 1). However, the number of monocytes adhering to endothelial cells returned to the basal level at $120 \mathrm{~min}$ after the glucose load. On the other hand, the saline injection did not cause any change in monocyte adhesion, and mannitol injection caused only a modest increase and only in non-branching areas (Fig. 1). These results suggest that a glucose injection provokes reversible monocyte adhesion to endothelial cells, which is not primarily due to an increase in blood osmolality. A temporary rise in blood glucose does not lead to a deterioration in endothelium-dependent vasodilation.

Many studies have assessed endothelial damage using endothelium-dependent vasodilation as an index.To assess the relationship between endothelium-dependent vasodilation and monocyte adhesion to endothelial cells, we investigated endothelium-dependent vasodilation using arteries isolated $30 \mathrm{~min}$ after injection of saline and glucose. Al-

b

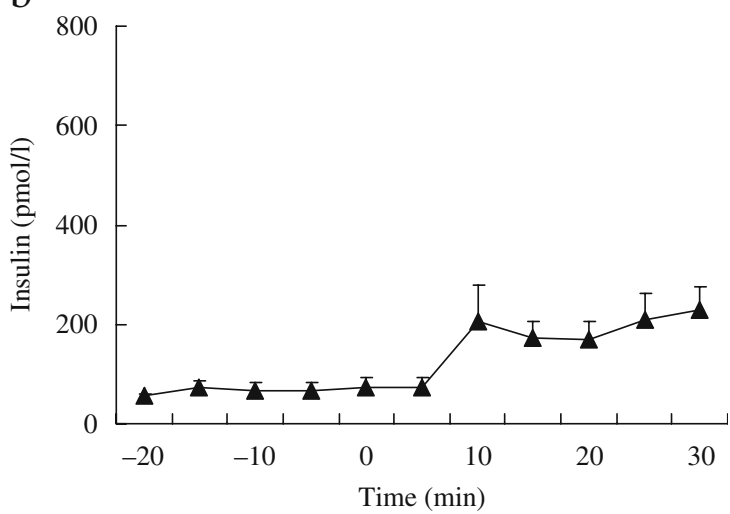

d

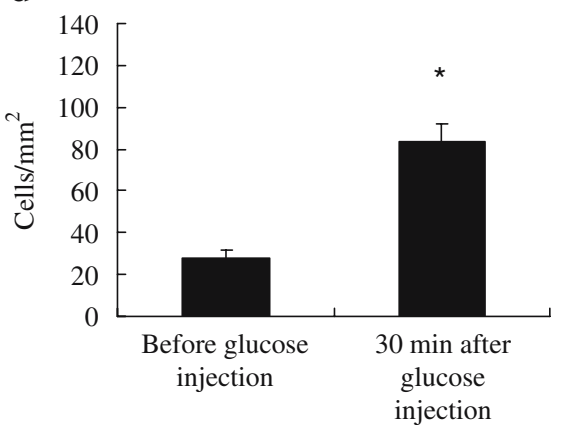

density of adhering monocytes in SD rats at a branching site (c) and non-branching area (d) just before and $30 \mathrm{~min}$ after the intravenous injection of $4.4 \mathrm{mmol} / \mathrm{kg}$ glucose $(n=5$, each) with continuous injection of octreotide. All data are expressed as means \pm SEM. $* p<0.05$ vs before glucose injection 
though increased monocyte adhesion to endothelial cells was confirmed in the arteries after glucose injection, we did not detect any deterioration in acetylcholine-dependent vasodilation in the glucose injection group (Fig. 2).

Elevated insulin levels are not associated with monocyte adhesion to endothelial cells provoked by glucose injection In our model, the glucose load was accompanied by an increase in intrinsic insulin secretion. To distinguish the effect of hyperglycaemia from that of elevated insulin, we infused octreotide, a somatostatin analogue, and adjusted the loading dose of glucose (to $4.4 \mathrm{mmol} / \mathrm{kg}$ ) so that the blood glucose level at $30 \mathrm{~min}$ was similar to that at $30 \mathrm{~min}$ after a glucose load $(5.5 \mathrm{mmol} / \mathrm{kg})$ without octreotide infusion. As shown in Fig. 3, the injection of glucose (4.4 $\mathrm{mmol} / \mathrm{kg}$ ) with octreotide resulted in a blood glucose level of $17.4 \pm 0.8 \mathrm{mmol} / \mathrm{l}$ at $30 \mathrm{~min}$ after the glucose injection. Octreotide infusion decreased the basal insulin level (Fig. 3b) and glucose injection with octreotide infusion caused only a modest increase of serum insulin (Fig. 3b). In rats injected with glucose and octreotide, the level of insulin after the glucose injection (Fig. 3b) was comparable with the basal level of insulin without infusion of octreotide (Fig. 1b). Under these conditions, we still observed an increase in monocyte adhesion to endothelial cells compared with before the injection of glucose with octreotide infusion (Fig. 3). To further investigate the effect of insulin on monocyte adhesion to endothelial cells, we infused insulin while maintaining euglycaemia $(\sim 4.4$ $\mathrm{mmol} / \mathrm{l}$ ) by infusing glucose for $30 \mathrm{~min}$, then determined the number of monocytes adhering to endothelial cells. As shown in Fig. 4, the rise of serum insulin alone without an
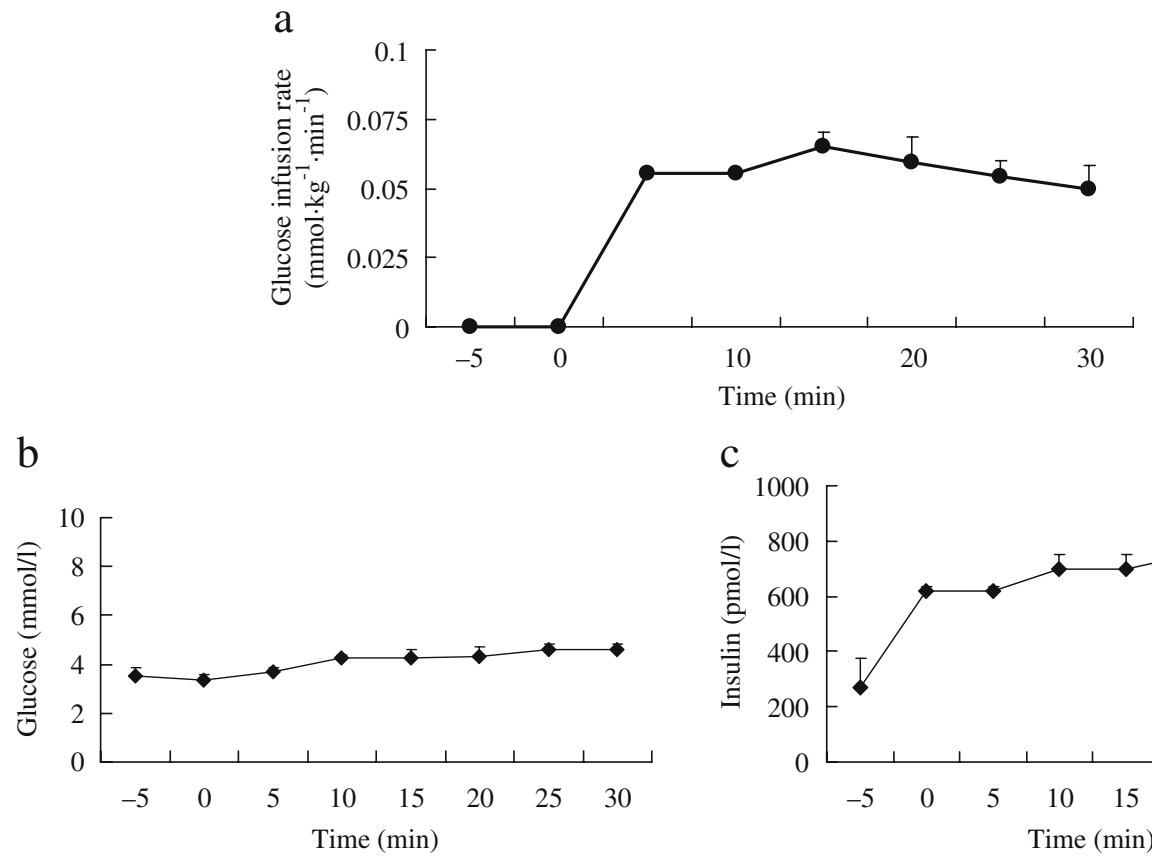

C

d

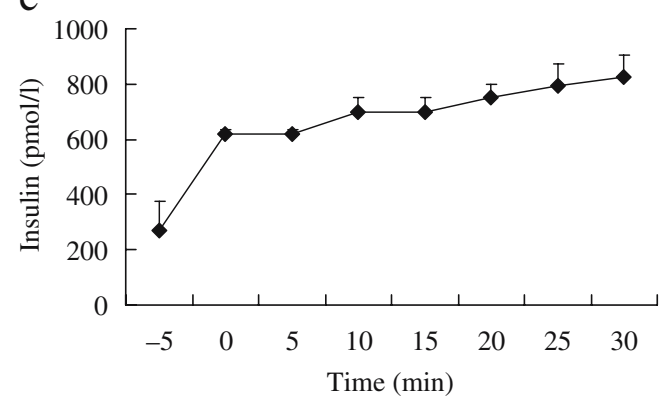

e

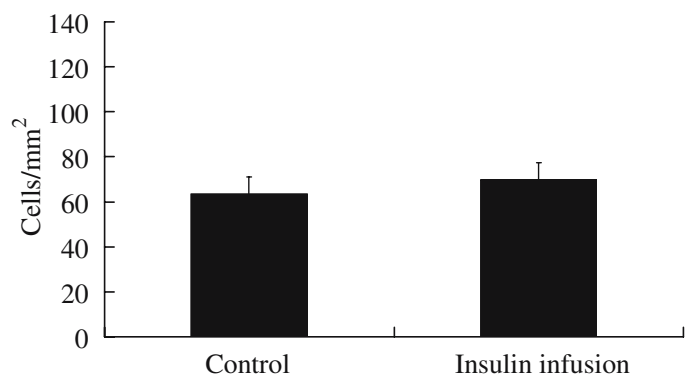

Fig. 4 Effect of insulin infusion in euglycaemic state on monocyte adhesion to endothelium. a-c Insulin ( $30 \mathrm{pmol} \mathrm{kg}^{-1} \mathrm{~min}^{-1}$ ) was continuously infused into 8-week-old SD rats. To maintain euglycaemia, glucose was simultaneously infused at variable rates, beginning with a dose of $0.055 \mathrm{mmol} \mathrm{kg} \mathrm{min}^{-1}$. Data represent (a) glucose infusion rate at the indicated time points, (b) blood glucose

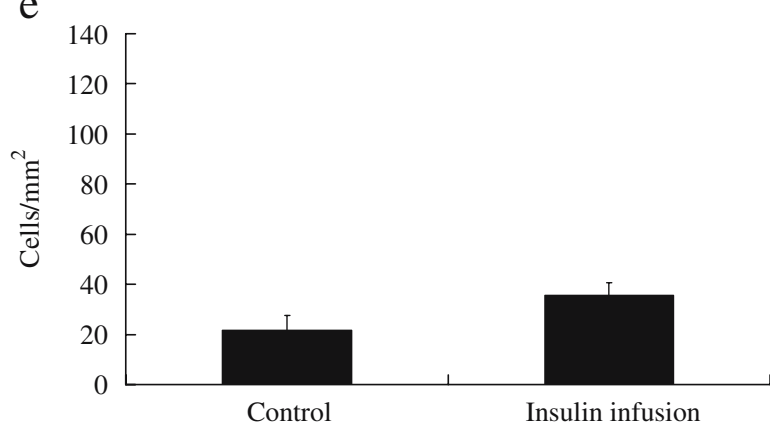

and (c) insulin, the latter two also measured at the indicated time points. $\mathbf{d}$ and e Density of adhering monocytes in SD rats at a branching site and non-branching area, respectively, at $30 \mathrm{~min}$ after hyperinsulinaemic-euglycaemic state $(n=5)$. As a control, the density of adherent monocytes in SD rats $30 \mathrm{~min}$ after $0.02 \mathrm{ml} \mathrm{kg}^{-1} \mathrm{~min}^{-1}$ saline infusion was calculated $(n=4)$. All data are expressed as means \pm SEM 
Table 1 Laboratory data before and 2 weeks after streptozotocin treatment in SD rats

\begin{tabular}{lccc}
\hline & Control & $\begin{array}{l}\text { STZ } \\
\text { (Group 1) }\end{array}$ & $\begin{array}{l}\text { STZ } \\
\text { (Group 2) }\end{array}$ \\
\hline Body weight (g) & $362.2 \pm 6.1$ & $316.6 \pm 10.4^{*}$ & $256.7 \pm 2.9^{*}$ \\
Glucose (mmol/1) & $3.8 \pm 0.2$ & $18.5 \pm 3.6^{*}$ & $19.6 \pm 2.1^{*}$ \\
Insulin (pmol/1) & $105 \pm 30.6$ & $71.4 \pm 1.7$ & $51.0 \pm 1.7^{* \dagger}$ \\
$\mathrm{HbA}_{1} \mathrm{c}(\%)$ & $2.7 \pm 0.2$ & $5.6 \pm 0.5^{*}$ & $6.6 \pm 0.1^{*}$ \\
$\begin{array}{l}\text { Triglyceride } \\
(\mathrm{mmol} / \mathrm{l})\end{array}$ & $0.22 \pm 0.05$ & $0.19 \pm 0.03^{*}$ & $0.18 \pm 0.03^{*}$ \\
$\begin{array}{l}\text { NEFA } \\
(\mathrm{mmol} / \mathrm{l})\end{array}$ & $0.25 \pm 0.00$ & $0.12 \pm 0.03^{*}$ & $0.10 \pm 0.02^{*}$ \\
$\begin{array}{l}\text { Total cholesterol } \\
(\mathrm{mmol} / \mathrm{l})\end{array}$ & $1.62 \pm 0.15$ & $1.20 \pm 0.11^{*}$ & $1.24 \pm 0.05^{*}$ \\
\hline
\end{tabular}

All data are expressed as means \pm SEM. Blood samples were collected in the fasting state

${ }^{*} p<0.05$ vs control groups; $\uparrow p<0.05$ vs Group 1

increase in glucose levels did not promote monocyte adhesion to endothelial cells. These findings indicate that a rise in insulin concentration is not associated with the enhanced monocyte adhesion to endothelial cells observed in our model.

a

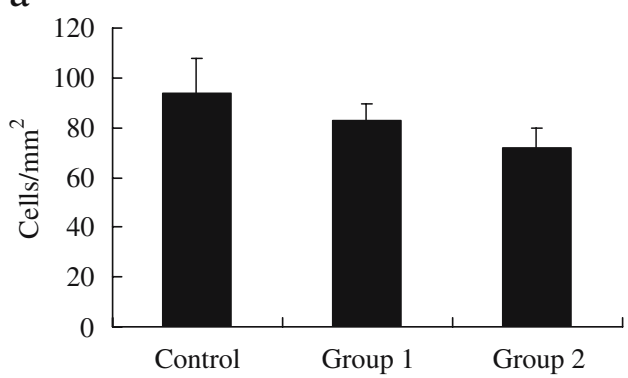

b

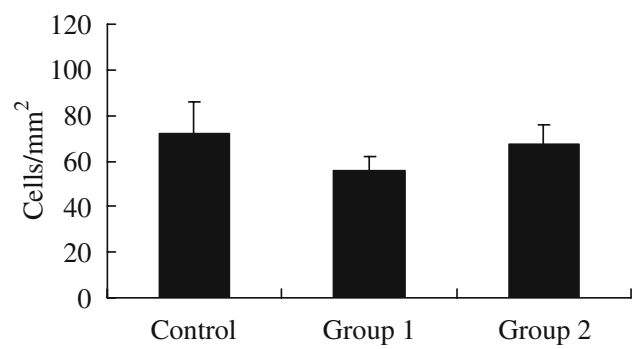

Fig. 5 Effect of sustained hyperglycaemia on monocyte adhesion to endothelium. Streptozotocin $(30 \mathrm{mg} / \mathrm{kg})$ was injected into 8 -weekold SD rats. Diabetic rats were divided into two groups according to blood glucose level at day 3 after streptozotocin (Group 1, blood glucose 15.5-26.5 mmol/1; Group 2, blood glucose $>26.5 \mathrm{mmol} / \mathrm{l}$ ). Two weeks after the injection, the density of adhering monocytes in SD rats at a branching site (a) and non-branching area (b) was counted. Ten-week-old rats with no treatment were used as control. All data are expressed as means \pm SEM
Increased monocyte adhesion to endothelial cells is not observed in rats 2 weeks after injection of low-dose streptozotocin The above results indicated that a temporary rise in blood glucose level promoted monocyte adhesion to endothelial cells. To distinguish between the effects of a temporary rise in blood glucose levels and those of sustained hyperglycaemia, we investigated whether hyperglycaemia sustained over a short period also promoted monocyte adhesion to endothelial cells. First, we injected low-dose streptozotocin $(30 \mathrm{mg} / \mathrm{kg})$ intravenously into SD rats at the age of 8 weeks. Three days after injection, we checked their non-fasting blood glucose levels, and rats with blood glucose level $>15.5 \mathrm{mmol} / \mathrm{l}$ were selected for further experiments. According to their non-fasting blood glucose level, we divided these rats into two groups (Group 1, blood glucose 15.5-26.5 mmol/1; Group 2, blood glucose $>26.5 \mathrm{mmol} / \mathrm{l}$ ) and investigated monocyte adhesion to endothelial cells in these rats 2 weeks after the injection of streptozotocin. These rats exhibited fasting hyperglycaemia with relatively low insulinaemia and their fasting blood glucose level was comparable with that at $30 \mathrm{~min}$ after glucose injection in SD rats without streptozotocin treatment (Fig. 1, Table 1). Under these conditions, no increase in monocyte adhesion to endothelial cells was observed, compared with that in untreated age-matched SD rats (Fig. 5). In contrast to the results from SD rats with temporary hyperglycaemia, these results indicate that exposure to consistent hyperglycaemia for 2 weeks does not promote monocyte adhesion to endothelial cells.

\section{Discussion}

In individuals exhibiting postprandial or post-challenge hyperglycaemia, many abnormalities of the postprandial state, including hypertriglyceridaemia, altered remnant particle clearance, and decreased LDL particle size, are also typical of the insulin-resistant state. Moreover, such individuals often exhibit hyperinsulinaemia. For effective diabetes management, therefore, it would be useful to clarify the role of each factor in the progression of atherosclerosis. In this study, we used non-obese and nondiabetic SD rats to determine the distinct role of the glucose 'spike'. A temporary rise in blood glucose, not consistent with hyperglycaemia for $\sim 2$ weeks, provoked a reversible increase in monocyte adhesion to endothelial cells in rats without insulin resistance. This effect was independent of increases in serum insulin levels.

Several studies have assessed the relation between hyperglycaemia and leucocyte binding to endothelial cells [14-17]. Although these studies used various experimental conditions and have their own meanings depending on the experimental conditions, most in vivo and in vitro studies have shown that hyperglycaemia induces leucocyte adhesion to endothelial cells. To the best of our knowledge, this is the first study to investigate the effect of a temporary rise in blood glucose on monocyte adhesion to non-diabetic rat aortic endothelial cells in vivo. 
The serious detrimental effects of glucose in cells are mainly explained by increased levels of glucose metabolites in the cells, following the increase in oxidative stress and activation of protein kinase $\mathrm{C}[18,19]$. If this is so, the degree of glycaemic exposure seems to be well related to the progression of atherosclerosis. Thus, our findings that the temporary rise of blood glucose, but not sustained hyperglycaemia, induced monocyte adhesion to endothelial cells seem unusual. Interestingly, however, other recent studies have demonstrated that intermittent hyperglycaemia resulted in an increase in apoptotic cell rate, oxidative stress, protein kinase $\mathrm{C}$ activation, and $\mathrm{NAD}(\mathrm{P}) \mathrm{H}$-oxidase activation in cultured endothelial cells, and that this was more pronounced than in states of persistent hyperglycaemia $[20,21]$. Taking these findings into account, monocyte adhesion to endothelial cells induced by a temporary rise in blood glucose might also be associated with the increase in oxidative stress. At present, the underlying mechanism remains unknown. However, during sustained hyperglycaemia, some adaptive mechanism might counteract the toxic glucose effect. On the other hand, because of the dramatic change of glucose concentration, such adaptive mechanisms might not work properly during temporary hyperglycaemia [21].

In the present study, we focused solely on the effect of hyperglycaemia. To avoid other effects on monocyte adhesion to endothelial cells, we used young (8-weekold), non-obese, and non-diabetic SD rats. In average diabetic patients, other factors, such as ageing, insulin resistance, and hypertriglyceridaemia might modify the effect of hyperglycaemia on monocyte adhesion to endothelial cells. Thus, it will be important in the future to elucidate the effects of possible co-existent factors on monocyte adhesion to endothelial cells triggered by hyperglycaemia.

Several studies have assessed endothelial damage in vivo using endothelium-dependent vasodilation as an index and reported that short-term hyperglycaemia in healthy subjects provokes temporary endothelial dysfunction as assessed by flow-mediated vasodilation [22-24]. On the other hand, Houben et al. [25] were unable to demonstrate a reduction in endothelium-dependent vasodilation by hyperglycaemia. Endothelium-dependent vasodilation depends on the action of nitric oxide, which interferes with key events in the development of atherosclerosis such as smooth muscle cell proliferation, plateletvessel wall interaction, and monocyte and leucocyte adhesion [26]. On the other hand, monocyte adhesion to endothelial cells does not necessarily depend solely on impaired nitric oxide action. Thus, the relationship between decreased endothelium-dependent vasodilation and monocyte adhesion to endothelial cells in vivo has not yet been clarified. In this study, we investigated endotheliumdependent vasodilation, using arteries isolated $30 \mathrm{~min}$ after a glucose load, and confirmed increased monocyte adhesion to endothelial cells. However, we did not observe any deterioration of endothelium-dependent vasodilation (Fig. 3). This suggests that monocyte adhesion to endo- thelium represents an aspect of endothelial damage that is distinct from endothelium-dependent vasodilation.

Monocyte adhesion to the endothelium is believed to be an initial step in the development of atherosclerosis and therefore clarification of the effect of potential atherogenic factors connected with monocyte adhesion to endothelial cells would contribute to a better understanding of the mechanism of atherosclerosis. However, our data only demonstrate that temporary hyperglycaemia in itself can induce monocyte adhesion to endothelial cells in vivo. To apply our findings to a clinical setting, the link between monocyte adhesion quantified by our method and the development of atherosclerosis needs to be elucidated.

Acknowledgements We thank Mrs. Yukiko Toyofuku and Naoko Daimaru for their excellent technical assistance. This work was supported by grants from the Takeda Science Foundation, Mitsukoshi Research Foundation and Mitsubishi Pharma Research Foundation (all to H. Watada).

Duality of interest The authors declare that they have no conflict of interest pertaining to this communication.

\section{References}

1. Haffner SM, Lehto S, Ronnemaa T, Pyorala K, Laakso M (1998) Mortality from coronary heart disease in subjects with type 2 diabetes and in nondiabetic subjects with and without prior myocardial infarction. N Engl J Med 339:229-234

2. Stamler J, Vaccaro O, Neaton JD, Wentworth D (1993) Diabetes, other risk factors, and 12-year cardiovascular mortality for men screened in the Multiple Risk Factor Intervention Trial. Diabetes Care 16:434-444

3. Stratton IM, Adler AI, Neil HA et al (2000) Association of glycaemia with macrovascular and microvascular complications of type 2 diabetes (UKPDS 35): prospective observational study. BMJ 321:405-412

4. UKPDS Study Group (1998) Intensive blood-glucose control with sulphonylureas or insulin compared with conventional treatment and risk of complications in patients with type 2 diabetes (UKPDS 33). UK Prospective Diabetes Study (UKPDS) Group. Lancet 352:837-853

5. Fuller JH, Shipley MJ, Rose G, Jarrett RJ, Keen H (1980) Coronary-heart-disease risk and impaired glucose tolerance. The Whitehall Study. Lancet 1:1373-1376

6. Donahue RP, Abbott RD, Reed DM, Yano K (1987) Postchallenge glucose concentration and coronary heart disease in men of Japanese ancestry. Honolulu Heart Program Diabetes 36:689-692

7. DECODE Study Group (1999) Glucose tolerance and mortality: comparison of WHO and American Diabetes Association diagnostic criteria. The DECODE study group. European Diabetes Epidemiology Group. Diabetes Epidemiology: Collaborative Analysis Of Diagnostic criteria in Europe. Lancet 354:617-621

8. Hanefeld M, Fischer S, Julius U et al (1996) Risk factors for myocardial infarction and death in newly detected NIDDM: the Diabetes Intervention Study, 11-year follow-up. Diabetologia 39:1577-1583

9. Temelkova-Kurktschiev TS, Koehler C, Henkel E et al (2000) Postchallenge plasma glucose and glycemic spikes are more strongly associated with atherosclerosis than fasting glucose or HbA1c level. Diabetes Care 23:1830-1834

10. Ross R (1999) Atherosclerosis - an inflammatory disease. N Engl J Med 340:115-126

11. Lusis AJ (2000) Atherosclerosis. Nature 407:233-241 
12. Azuma K, Watada H, Niihashi M et al (2003) A new En face method is useful to quantitate endothelial damage in vivo. Biochem Biophys Res Commun 309:384-390

13. Iesaki T, Gupte SA, Kaminski PM, Wolin MS (1999) Inhibition of guanylate cyclase stimulation by $\mathrm{NO}$ and bovine arterial relaxation to peroxynitrite and $\mathrm{H}_{2} \mathrm{O}_{2}$. Am J Physiol 277:H978H985

14. Kim JA, Berliner JA, Natarajan RD, Nadler JL (1994) Evidence that glucose increases monocyte binding to human aortic endothelial cells. Diabetes 43:1103-1107

15. Hadcock S, Richardson M, Winocour PD, Hatton MW (1991) Intimal alterations in rabbit aortas during the first 6 months of alloxan-induced diabetes. Arterioscler Thromb 11:517-529

16. Morigi M, Angioletti S, Imberti B et al (1998) Leukocyteendothelial interaction is augmented by high glucose concentrations and hyperglycemia in a NF-kB-dependent fashion. J Clin Invest 101:1905-1915

17. Ramos CL, Huo Y, Jung U et al (1999) Direct demonstration of P-selectin- and VCAM-1-dependent mononuclear cell rolling in early atherosclerotic lesions of apolipoprotein E-deficient mice. Circ Res 84:1237-1244

18. Ceriello A, Motz E (2004) Is oxidative stress the pathogenic mechanism underlying insulin resistance, diabetes, and cardiovascular disease? The common soil hypothesis revisited. Arterioscler Thromb Vasc Biol 24:816-823

19. Beckman JA, Creager MA, Libby P (2002) Diabetes and atherosclerosis: epidemiology, pathophysiology, and management. JAMA 287:2570-2581
20. Quagliaro L, Piconi L, Assaloni R et al (2003) Intermittent high glucose enhances apoptosis related to oxidative stress in human umbilical vein endothelial cells: the role of protein kinase $\mathrm{C}$ and NAD(P)H-oxidase activation. Diabetes 52:2795-2804

21. Risso A, Mercuri F, Quagliaro L, Damante G, Ceriello A (2001) Intermittent high glucose enhances apoptosis in human umbilical vein endothelial cells in culture. Am J Physiol Endocrinol Metab 281:E924-E930

22. Akbari CM, Saouaf R, Barnhill DF et al (1998) Endotheliumdependent vasodilatation is impaired in both microcirculation and macrocirculation during acute hyperglycemia. J Vasc Surg 28:687-694

23. Kawano H, Motoyama T, Hirashima O et al (1999) Hyperglycemia rapidly suppresses flow-mediated endothelium-dependent vasodilation of brachial artery. J Am Coll Cardiol 34:146154

24. Shige H, Ishikawa T, Suzukawa M et al (1999) Endotheliumdependent flow-mediated vasodilation in the postprandial state in type 2 diabetes mellitus. Am J Cardiol 84:1272-1274

25. Houben AJ, Schaper NC, de Haan CH (1996) Local 24-h hyperglycemia does not affect endothelium-dependent or -independent vasoreactivity in humans. Am J Physiol 270:H2014 $\mathrm{H} 2020$

26. Calles-Escandon J, Cipolla M (2001) Diabetes and endothelial dysfunction: a clinical perspective. Endocr Rev 22:36-52 